\title{
Clinical Features of Herniated Disc at Cervicothoracic Junction Level Treated by Anterior Approach
}

\author{
Jun Gue Lee ${ }^{1}$, Hyeun Sung $\mathrm{Kim}^{2}$, Chang $\mathrm{II} \mathrm{Ju}^{1}$, Seok Won Kim ${ }^{1}$ \\ ${ }^{I}$ Department of Neurosurgery, Chosun University College of Medicine, Gwangju, \\ ${ }^{2}$ Department of Neurosurgery, Nanoori Hospital, Suwon, Korea
}

\begin{abstract}
Objective: The anterior approach for $\mathrm{C} 7-\mathrm{T} 1$ disc herniation may be challenging because of obstruction by the manubrium and the narrow operative field. This study aimed to investigate the clinical and neurological outcomes of anterior approach for $\mathrm{C} 7-\mathrm{T} 1$ disc herniation.

Methods: We retrospectively evaluated 13 patients who underwent the anterior approach for $\mathrm{C} 7-\mathrm{T} 1$ disc herniation by a single surgeon within a period of 11 years (2003-2014). The minimum follow-up duration was 6 months. We describe the clinical presentation, radiographic findings, neurological outcome, and related complications.

Results: Of 372 patients with single-level anterior discectomy and fusion or artificial disc replacement for cervical disc herniation, $13(3.5 \%)$ had C7-T1 disc herniation. The main clinical presentation was unilateral motor weakness in intrinsic hand muscles (11 patients), along with numbness, pain, and tingling sensation that radiate down the arm to the little finger. Most of the patients improved after surgery via the anterior approach. Ten patients underwent successful anterior discectomy and fusion by the standard supramanubrial Smith-Robinson approach, but 2 needed additional manubriotomy and sternotomy. In 1 patient, we performed surgery at a wrong level because the correct level was difficult to identify intraoperatively. Two patients had transient vocal dysfunction, but none had major complications related to injuries of the great vessels such as the thoracic duct or esophagus. Conclusion: For patients who require direct anterior decompression for $\mathrm{C} 7-\mathrm{T} 1$ disc herniation, the anterior approach is relatively feasible. However, care should be taken to overcome physical constraints by the manubrium and slope.
\end{abstract}

Key Words: Cervicothoracic · Anterior · Fusion

\section{INTRODUCTION}

Most cervical disc herniations occur between the $\mathrm{C} 3$ to $\mathrm{C} 7$ disc space. Disc herniations at the C7-T1 level, the cervicothoracic junction (CTJ), are rare, accounting for only $4 \%$ to $8 \%$ of all cervical disc herniation cases ${ }^{1,3)}$.

In some cases of C7-T1 herniation, the neurological presentation and operative technique do not differ from those for other levels of the cervical spine. However, in other cases, C7-T1 herniations are not distinctly similar to herniations at other levels of the cervical spine. Hence, access to C7-T1 disc herniations through the anterior aspect may be difficult

- Received: January 6, 2016 • Revised: March 15, 2016

- Accepted: April 6, 2016

Corresponding Author: Seok Won Kim

Department of Neurosurgery, Chosun University Hospital, Chosun

University College of Medicine, 365 Pilmun-daero, Dong-gu, Gwangju 61453, Korea

Tel: +82-62-220-3126, Fax: +82-62-227-4575

E-mail: ns64902@hanmail.net

@This is an open access article distributed under the terms of the Creative Commons Attribution Non-Commercial License (http://creativecommons.org/licenses/by-nc/4.0/) which permits unrestricted non-commercial use, distribution, and reproduction in any medium, provided the original work is properly cited. because of restrictions caused by imposed obstructions by bone structures, the slope of the vertebral bodies, and the vital struc- tures. However, reports in the literature regarding the anterior approach for $\mathrm{C7}-\mathrm{T} 1$ disc herniation are $\mathrm{few}^{4,8)}$. Thus, we report our experience with the anterior approach for the treatment of C7-T1 disc herniation, with regard to clinical presentation, limitations of operative exposure, and neurological outcome.

\section{MATERIALS AND METHODS}

We retrospectively reviewed the medical records of 372 patients who underwent an anterior approach such as anterior cervical discectomy and fusion and artificial disc replacement for single-level cervical disc herniation by a single surgeon between 2003 and 2014.

Among the 372 patients with single-level disc herniation, 13 patients (3.5\%), who underwent the anterior approach for disc herniation at the C7-T1 level were included in this study. Radiographic evaluation was conducted through imaging studies, including plain radiography, computed tomography (CT), and magnetic resonance imaging (MRI). The patients were evaluated for clinical presentation, radiographic findings, neurological outcome, and surgery-related complications. 


\section{RESULTS}

The clinical data of the patients in our series are summarized in (Table 1). The mean age of the patients was 55.5 years (range, 39-70 years). Eleven patients had unilateral upper limb weakness and pain radiating from the shoulder to the lateral aspect of the hand, but 2 patients had only pain radiating down the arm to the little finger. Motor deficits were grade IV in 10 patients and grade III in 1 patient. All of the patients were followed up for a minimum of 6 months, with a mean follow-up period of $10.2 \pm 9.4$ months.

In 10 of the 13 patients, the anterior approach could be performed via the standard supramanubrial Smith-Robinson approach (Fig. 1). Two patients needed additional manubriotomy and sternotomy to allow for adequate visualization (Fig. 2). In 1 patient, we unintentionally performed surgery at a wrong level because the correct level was difficult to confirm intraoperatively owing to the bulk of both shoulders.

All of the patients, except one who underwent a wrong-level surgery, had improved in terms of motor function and pain by the final follow-up evaluation. They obtained excellent or good outcome according to modified MacNab's criteria. An anterior cervical plate was placed in just 2 of the 13 patients, and only a polyetheretherketone cage (Solis, Stryker, Kalamazoo, MI, USA) with a filling autogenous iliac crest graft was placed in the remaining patients, in whom placement of a cervical plate was difficult due to a narrow surgical field.

None of the patients had migration of the stand-alone cage or plate during follow-up period and major complications related to injuries of the great vessels such as the thoracic duct and esophagus. Two patients had transient vocal dysfunction, which had completely returned to normal by the final followup. Two patients who needed manubriotomy and sternotomy complained of excruciating pain at the surgical site in spite of continuous medications, including narcotics, during the followup period.
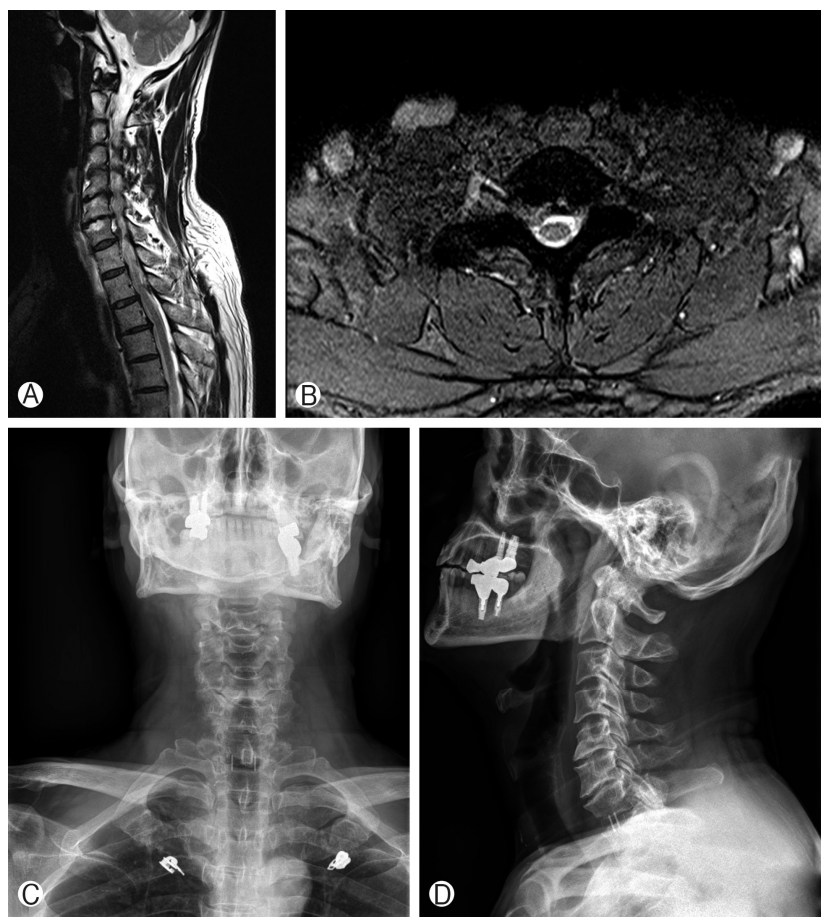

Fig. 1. A 58-year old man who had right C7-T1 disc herniation. (A, B) Sagittal and axial T2-weighted magnetic resonance images reveal a laterally herniated soft disc at the right C7-T1 level. (C, D) Postoperative simple radiographs show anterior cervical discectomy and fusion was performed by a standard supramanubrial approach.

Table 1. Clinical characteristics of the patients with C7-T1 disc herniation

\begin{tabular}{|c|c|c|c|c|c|c|c|c|}
\hline Case & $\begin{array}{l}\text { Age }(y r) / \\
\text { sex }\end{array}$ & $\begin{array}{l}\text { Motor weakness in the } \\
\text { intrinsic hand muscle }\end{array}$ & Side & $\begin{array}{l}\text { Plate } \\
\text { use }\end{array}$ & $\begin{array}{l}\text { Manubriotomy } \\
\text { or sternotomy }\end{array}$ & Complication & $\begin{array}{l}\text { Follow-up } \\
\text { (mo) }\end{array}$ & Outcome \\
\hline 1 & $58 / \mathrm{M}$ & 4 & Right & No & No & - & 6 & Excellent \\
\hline 2 & $48 / \mathrm{F}$ & 4 & Right & No & No & - & 8 & Excellent \\
\hline 3 & $42 / \mathrm{M}$ & 4 & Left & No & Yes & Severe operative site pain & 20 & Good \\
\hline 4 & 39/M & 4 & Left & Yes & No & Transient vocal cord dysfunction & 10 & Excellent \\
\hline 5 & $53 / \mathrm{M}$ & 3 & Right & No & No & Transient vocal cord dysfunction & 12 & Good \\
\hline 6 & $62 / \mathrm{F}$ & 4 & Right & Yes & No & - & 12 & Excellent \\
\hline 7 & $59 / \mathrm{F}$ & Intact & Left & No & No & - & 7 & Excellent \\
\hline 8 & $63 / \mathrm{M}$ & 4 & Left & No & Yes & Severe operative site pain & 9 & Excellent \\
\hline 9 & $43 / \mathrm{M}$ & 4 & Left & No & No & - & 7 & Excellent \\
\hline 10 & $60 / \mathrm{F}$ & 4 & Right & No & No & Wrong-level surgery & 10 & Poor \\
\hline 11 & $70 / \mathrm{M}$ & 4 & Right & No & No & - & 6 & Excellent \\
\hline 12 & $56 / \mathrm{F}$ & 4 & Left & No & No & - & 10 & Excellent \\
\hline 13 & $69 / \mathrm{M}$ & Intact & Right & No & No & - & 12 & Excellent \\
\hline
\end{tabular}



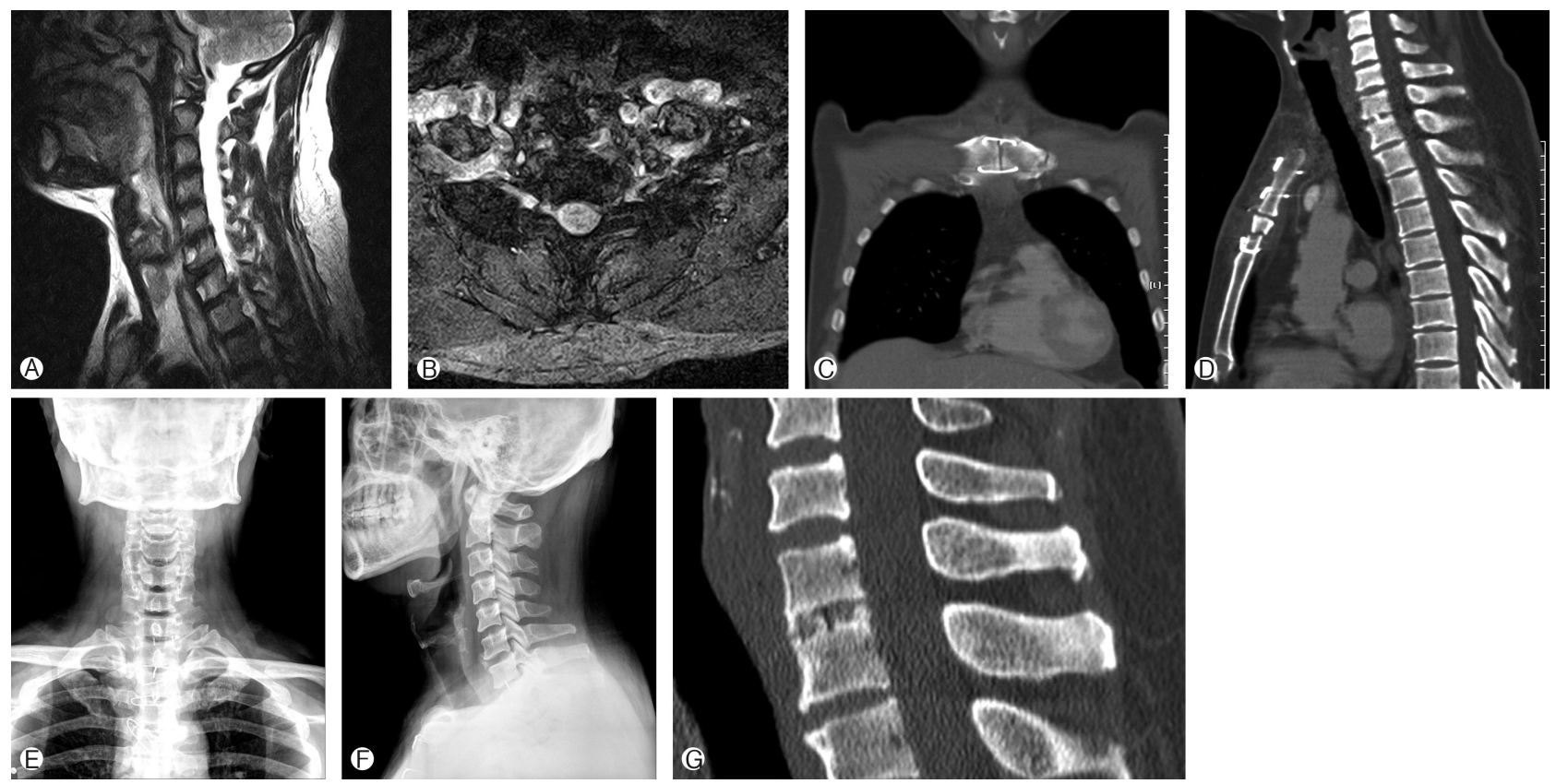

Fig. 2. A 42-year-old man who had left C7-T1 disc herniation. (A, B) Sagittal and axial T2-weight magnetic resonance image show a laterally herniated soft disc at the left C7-T1 level. (C, D) Postoperative computed tomography scans reveal the finding of manubriotomy and sternotomy. (E, F) Postoperative simple radiographs show anterior cervical discectomy and fusion was performed through a manubriotomy and sternotomy. (G) Computed tomography scan at 11 months after surgery reveals bone fusion was obtained.

\section{DISCUSSION}

Decompression of an anterior lesion at the CTJ may be challenging because the sternum and the slope of the vertebral bodies away from the surgeon act as physical constraints that obscure the surgical field. Moreover, patients are at risk of iatrogenic injury of the thoracic duct and recurrent laryngeal nerve because of overlying structures and individual variations in bone anatomy. On the contrary, as the posterior approach cannot be used to remove the anterior herniated disc, performing it alone may also result in an incomplete surgery. In our study, 10 of the 13 patients obtained good or excellent clinical outcome with the supramanubrial Smith-Robinson approach at the C7-T1 level, without additional manubriotomy and sternotomy. However, 2 patients who were husky and obese men needed manubriotomy and sternotomy to ventrally approach the C7-T1 disc herniation. Moreover, 1 patient underwent operation at a wrong level because the correct level was difficult to confirm intraoperatively owing to the bulk of both shoulders.

The supramanubrial Smith-Robinson approach is familiar to spine neurosurgeons and less invasive. In patients with slim and long necks, the exposure can reach as low as the T3 level, which allows access to the upper thoracic spine via the standard anterior approach, without manubriotomy or sternotomy. However, it is limited by the variation in vertebral body at the level of the suprasternal notch, especially for obese pa- tients who have husky and short necks ${ }^{2)}$.

All of our patients presented with unilateral radiculopathy rather than myelopathy. This is thought to be caused by the unique features of the C7-T1 disc space. Unlike other levels of upper disc spaces, the Luschka joints are usually absent at the C7-T1 disc space. For this reason, C7-T1 disc herniation is prone to herniate laterally rather than centrally, causing myelopathy. Our results also support this, because all of our patients showed unilateral radiculopathy.

Another clinical feature of $\mathrm{C} 7-\mathrm{T} 1$ disc herniation is motor deficit in the intrinsic hand muscles. The C8 nerve root, which is usually compressed by C7-T1 disc herniation, is composed predominantly by motor fibers that are responsible for the innervations of the intrinsic hand muscles ${ }^{8)}$. MRI is considered as the modality of choice for imaging neural elements and the spinal cord in cervical disc herniations. However, C7-T1 disc herniation is more difficult to diagnose than other herniations in upper regions because of the overlying soft tissues. Hence, attention should be focused on this level in case of characteristics of C7-T1 disc herniation are evident ${ }^{6,7}$. Fraser et al. ${ }^{5)}$ suggested that preoperative MRI could be an efficient tool for determining the adequate approaches for the CTJ for anterior spine fusion. However, in spite of their trial to establish objective criteria to assist neurosurgeons in choosing the suitable approach for the CTJ, the algorithm they derived was not exact, with scarce consideration of important soft-tissue anatomy.

Falavigna et al. ${ }^{4)}$ recommended against the use of standalone cages alone at the C7-T1 level because of the risk of cage 
displacement by extrusion. They reported that 2 of 10 patients with stand-alone cages required reoperation for extrusion of the cage. However, in our study, we observed no displacement of the stand-alone cages that required reoperation. Some authors reported that this level represents the transition from the lordotic and fairly mobile cervical spine to the kyphotic and quite rigid thoracic spine. Because of this biomechanical difference, this region is subjected to more static and dynamic stresses ${ }^{9)}$.

This study has some limitations. In spite of the relatively good clinical outcome after the anterior approach, we had no objective clinical outcome measures and could not conduct fusion assessment because of the short follow-up period. To assess the fusion status at the C7-T1 level, CT results are usually essential and thus should be confirmed. However, this study was focused on investigating whether the anterior approach was a feasible technique in the treatment of C7-T1 disc herniations without manubriotomy and sternotomy. Further study based on the point of solid fusion and objective clinical outcome with a large number of patients and longer follow-up period will be necessary in the future.

\section{CONCLUSION}

The anterior approach is more difficult to perform at the CTJ than at other cervical levels because of the anatomical features of the CTJ. Although most cases of C7-T1 disc herniation can be treated by using the supramanubrial SmithRobinson technique, understanding the pertinent anatomy of individual patients and its limitation is important.

\section{CONFUCT OF INTEREST}

No potential conflict of interest relevant to this article was reported.

\section{REFERENCES}

1. Adamson TE: Microendoscopic posterior cervical laminoforaminotomy for unilateral radiculopathy: results of a new technique in 100 cases. J Neurosurg 95(1 Suppl):51-57, 2001

2. An HS, Vaccaro A, Cotler JM, Lin S: Spinal disorders at the cervicothoracic junction. Spine (Phila Pa 1976) 19:2557-2564, 1994

3. Bucciero A, Vizioli L, Cerillo A: Soft cervical disc herniation. An analysis of 187 cases. J Neurosurg Sci 42:125-130, 1998

4. Falavigna A, Righesso O, Betemps A, Vela de los Rios PF, Guimarães R, Ziegler M, et al: Surgical planning and neurological outcome after anterior approach to remove a disc herniation at the C7-T1 level in 19 patients. Spine (Phila Pa 1976) 39:E219225,2014

5. Fraser JF, Diwan AD, Peterson M, O'Brien MF, Mintz DN, Khan $\mathrm{SN}$, et al: Preoperative magnetic resonance imaging screening for a surgical decision regarding the approach for anterior spine fusion at the cervicothoracic junction. Spine (Phila Pa 1976) 27:675681, 2002

6. Kim MS, Kim SH, Kim SW, Chang CH, Cho SH, Bae JH: Anterior cervical interbody fusion with carbon-composite cages and local autobone for cervical disc disease. J Korean Neurosurg Soc 34:115-118, 2003

7. Park SJ, Kim SB, Kim MK, Lee SH, Oh IH: Clinical features and surgical results of cervical myelopathy caused by soft disc herniation. Korean J Spine 10:138-143, 2013

8. Post NH, Cooper PR, Frempong-Boadu AK, Costa ME: Unique features of herniated discs at the cervicothoracic junction: clinical presentation, imaging, operative management, and outcome after anterior decompressive operation in 10 patients. Neurosurgery 58:497-501, 2006

9. Wang VY, Chou D: The cervicothoracic junction. Neurosurg Clin N Am 18:365-371, 2007 